\title{
DE YAPEYÚ A ARECO Y LAS CREENCIAS DE LA GENTE COMÚN. UN RECORRIDO POR LA HUELLA DE JUAN CARLOS GARAVAGLIA
}

\author{
María Elena Barral \\ Instituto Ravignani-UBA-CONICET/UNLu \\ (Buenos Aires - Luján, Argentina) \\ magnebarral@gmail.com
}

El artículo reconstruye una trayectoria bistoriográfica que sigue una dirección precisa: desde la historia agraria de la campaña bonaerense colonial hasta la historia del catolicismo durante el mismo periodo. Al repasarla no podemos -y no queremos- evitar nombrar a quienes abrieron los primeros surcos. Juan Carlos Garavaglia dirigió buena parte de este impulso renovador. A partir de un profundo conocimiento del mundo campesino preindustrial y a través de un paciente y monumental trabajo de archivo, Garavaglia descubrió una sociedad ignorada por casi todos: hombres, mujeres, familias, tradiciones, costumbres, conflictos y relaciones de poder. Estos hallazgos pusieron en entredicho viejos mitos y nos permitieron imaginar un mundo de creencias y prácticas religiosas y de sotanas polvorientas.

Palabras CLAVE: historiografía, historia agraria, Rio de la Plata, catolicismo.

\section{FRoM YAPEYU TO ARECO AND THE COMMON PEOPLE'S BELIEFS. A TOUR OF THE TRACE OF JUAN CARLOS GARAVAGLIA}

The article reconstructs a historiographical path that follows a precise direction: from the agrarian bistory of the colonial Buenos Aires countryside to the bistory of Catholicism during the same period. When reviewing it we can not — and do not want to-avoid naming those who opened the first furrows. Juan Carlos Garavaglia led a good part of this renovating impulse. From a deep knowledge of the pre-industrial peasant world and through a monumental and patient archive work, Garavaglia brought to light a society ignored by almost everyone: men, women, families, traditions, customs, conflicts and power relations. 
These discoveries challenged old myths and allowed us to imagine a world of religious beliefs and practices and dusty cassocks.

KEYWORDS: historiopraphy, agrarian history, Rio de la Plata, catholicism.

\section{Introducción}

La historia de la Iglesia católica en el Río de la Plata durante el período colonial y las primeras décadas del siglo XIX ha experimentado, en las últimas tres décadas, una importante renovación en sus aproximaciones. Hasta entonces, sólo conocíamos aspectos formales del funcionamiento de algunas de las más altas autoridades e instituciones de la Iglesia diocesana y poco o nada sobre las más modestas parroquias rurales, de indios o de españoles.

En el mismo sentido, los cambios que se dieron en la esfera eclesiástica a partir de la Revolución de Mayo, contaban con estudios específicos, si bien en la mayoría de los casos se trataba de versiones «edificantes» del pasado eclesiástico preocupadas por demostrar la intervención de la Iglesia — y sólo de algunas de sus instituciones- en los principales acontecimientos de la «nación» y presentándola como católica desde su mismo origen. En suma, el papel de los dispositivos y agentes religiosos en la construcción cotidiana del orden social y político no era considerada una dimensión de análisis relevante.

Algunas de las vías que favorecieron la renovación de los estudios sobre el catolicismo se nutrieron de investigaciones desarrolladas en campos historiográficos vecinos que no tenían en el centro de sus preocupaciones a las instituciones eclesiásticas ni a las creencias religiosas. En esta oportunidad me interesa reflexionar acerca del modo en que la historia rural rioplatense impulsó una manera de pensar la historia del catolicismo. Afortunadamente, y como consecuencia de un fructífero diálogo, la historia nos da la oportunidad para restablecer las interrelaciones que la historiografía —en sus necesarias especializaciones y dinámicas particulares- habían soslayado.

Es evidente que algunas historias no pueden escapar a los nombres propios. La que buscamos reseñar en esta oportunidad también la tiene: Juan Carlos Garavaglia. Sin su empeño en revisar algunos de los mitos fundacionales de la nación argentina es probable que el camino recorrido ni siquiera se hubiera iniciado.

\section{El problema: de la historia rural a la historia de los curas y las parroquias}

Desde comienzos de la década de 1980 y durante casi cuatro décadas la historia rural rioplatense del siglo XVIII a mediados del XIX —en especial lo que hoy se conoce como pampa húmeda - ha tenido un desarrollo muy importante. Esta historia rural pampeana se inspiró en gran medida en la historiografía sobre la hacienda colonial hispanoamericana que había tenido un desarrollo más temprano en otras regiones como en México. La 
inclusión de la historia rural rioplatense en las líneas matrices de su «congénere latinoamericana» fue, sin embargo, tardía y parcial. ${ }^{1}$ Como sucedió en la mayor parte de la historia agraria del continente, la imagen que había predominado hasta hace algunas décadas era la de un mundo rural dominado por la gran propiedad. Los primeros estudios serios y de casos concretos de establecimientos productivos rioplatenses —el nombre local: estancias - fueron los dos casos incluidos en el Simposio de Roma de 1972 organizado por la Comisión de Historia Económica de CLACSO en el marco del XL Congreso Internacional de Americanistas el cual dio origen a la compilación de Enrique Florescano Haciendas, latifundios y plantaciones. ${ }^{2}$

Este libro ofrecía el panorama más completo para entonces sobre los estudios de las grandes propiedades agrarias en la historia latinoamericana y dos argentinos - Tulio Halperin Donghi ${ }^{3}$ y Juan Carlos Garavaglia ${ }^{4}$ - participaban con trabajos sobre las estancias rioplatenses. Según Raúl Fradkin se trataba de «los primeros esfuerzos por conocer en profundidad los establecimientos productivos y, como en el resto de América, lo hicieron sobre la segunda mitad del siglo XVIII y a partir de establecimientos eclesiásticos».5 El artículo de Garavaglia estuvo destinado a la estancia jesuítica del pueblo de indios de Yapeyú, en el momento posterior a la expulsión de los jesuitas y tiene la impronta de los debates de la época sobre los modos de producción. ${ }^{6}$ Este tipo de estudios no llegó a alcanzar arraigo institucional por varios motivos y entre los principales se encuentra la ruptura y crisis del sistema universitario y científico que implicó la dictadura militar. El relanzamiento de la historia agraria colonial rioplatense debió esperar al fin de la dictadura y a la reconstitución de las universidades y centros de investigación. Pero, como señala Fradkin este relanzamiento presenta una imagen paradojal ya que, por un lado, había una cierta continuidad en la selección de temas, pero, por otro lado, se verifica un cambio sustancial de los métodos y las preguntas que orientaron las investigaciones. De cualquier

1. Fradkin, Raúl, «Caminos abiertos en la pampa. Dos décadas de renovación de la historia rural rioplatense desde mediados del siglo XVIII a mediados del XIX», en Gelman, Jorge (comp.), La historia económica argentina en la encrucijada. Balances y perspectivas, Buenos Aires, Prometeo Libros, 2006, p. 205.

2. Florescano, Enrique (coord.), Haciendas, latifundios y plantaciones en América Latina, Mexico DF, Siglo XXI, 1975.

3. Halperin Donghi, Tulio, «Una estancia en la campaña de Buenos Aires, Fontezuela, 1753-1809», en Florescano, Enrique (coord.), Haciendas, latifundios y plantaciones en América Latina, Mexico DF, Siglo XXI, 1975, pp. 446-463.

4. Garavaglia, Juan Carlos, «Las actividades agropecuarias en el marco de la vida económica del pueblo de indios de Nuestra Señora de los Santos Reyes Magos de Yapeyú, 1768-1806», en Florescano, Enrique (coord.), Haciendas, latifundios y plantaciones en América Latina, Mexico DF, Siglo XXI, 1975, pp. 464-485.

5. Fradkin, Raúl «La historia agraria y los estudios de establecimientos productivos en Hispanoamérica: una mirada desde el Río de la Plata», en Fradkin, Raúl (comp. y estudio preliminar), La historia agraria del Río de la Plata colonial. Los establecimientos productivos I, Buenos Aires, CEAL, 1993, p. 17.

6. En el segundo párrafo del artículo Garavaglia sostiene: «Si bien el sistema productivo imperante en estos pueblos quizás no puede ser definido estrictamente de acuerdo a algunos de los modos de producción "clásicos" enumerados por Marx, podemos decir en forma provisoria, que su régimen de producción, en el nivel estricto de la "región" económica, es semejante al despótico-aldeano» Garavaglia, Juan Carlos, «Las actividades agropecuarias...», cit., pp. 464-465. 
modo, según el mismo autor «algo resulta claro: muchas de las preguntas que han orientado parte importante de la investigación provienen de aquellos debates de hace más de treinta años». ${ }^{7}$

Desde este punto, con varios comienzos entre las décadas de 1970 y 1980, a partir de la iniciativa de varios jóvenes historiadores que vivieron su juventud en los años '60 y en los '70 — muchos de ellos, durante su exilio político — tuvo lugar la renovación de la historia rural pampeana.

Como consecuencia de ella, la imagen de estas áreas rurales — conocida en las fuentes como «la campaña bonaerense»— ha cambiado de manera contundente. Esta producción historiográfica proporcionó nuevas conclusiones en cuanto a las relaciones sociales y puso de manifiesto una complejidad insospechada. Lo insospechado está ligado a la impronta de la historiografía tradicional para la cual existía una campaña poblada por peones y «gauchos» (hombres solos) en un territorio dominado por la gran propiedad ganadera. Por el contrario, en la región se fueron configurando diversos ecosistemas social-agrarios en los cuales adquirió características diferenciadas el proceso de estructuración social.

Por su parte, las investigaciones sobre los procesos migratorios mostraron la presencia de tradiciones y costumbres religiosas de larga data, que contradicen aquella imagen de «desierto» o de «nada sociológica» ${ }^{8}$ que durante tantos años prevaleció acerca de la historia rural en esta región y en este período. En la descripción de Juan Carlos Garavaglia el par ideal asociado a la imagen de desierto es el gaucho «surgido de la nada y vagante $\sin$ rumbo por esas soledades pampeanas». La nueva imagen que surge luego de la acumulación de investigaciones sobre la región revela la existencia de comunidades en formación al ritmo de la ocupación territorial, que afirmaron un tipo de producción - ganadera y/o cerealera - en variadas escalas, que dieron vida a distinto tipo de intercambios mercantiles y que participaron en la construcción de un orden institucional en el cual las instituciones eclesiásticas tuvieron un papel fundante.

Aquella idea de «nada sociológica» y de «vacío social», que estas investigaciones contribuyeron a poblar de relaciones sociales, incluía a la Iglesia y a la dimensión religiosa de la vida de los varones y mujeres del campo de Buenos Aires. La historia rural al mostrar unas comunidades más complejas también favoreció la formulación de preguntas en torno a los procesos de articulación y control social y permitió explorar acerca del modo en que instituciones y agentes religiosos podían intervenir en los mismos. A partir de estas hipótesis se fueron desarrollando distintas investigaciones que mostraron cómo los párrocos fueron los principales intermediarios en las zonas rurales de Buenos Aires y pusieron

7. Refiriéndose a este debate sobre los Modos de Producción en América Latina, se pregunta en este artículo del año 2006: «¿Habrá llegado el momento de replantear aquella discusión? Por cierto, no en los mismos términos, ni con las mismas resonancias; por cierto, también con evidencias más firmes y métodos más complejos y sofisticados. Pero no deja de ser paradójico que hoy en día sepamos mucho más acerca de los medios de producción, de las fuerzas productivas y de las relaciones de producción que cuando se intentaba definirlos con más imaginación teórica que evidencias», Fradkin, Raúl, «Caminos abiertos...», cit., p. 205.

8. Garavaglia, Juan Carlos, «De mingas y convites: la reciprocidad campesina entre los paisanos rioplatenses», en Anuario del IEHS, núm. 12, Tandil, 1997, p. 131. 
de manifiesto su papel en el gobierno local y en el control social a través de muy diversos modos de intervención. ${ }^{9}$

De modo que la investigación sobre la Iglesia en el mundo rural bonaerense, que nace en diálogo con esta renovación, focaliza en una serie de líneas de trabajo. Algunas de ellas — que comentamos brevemente a continuación - se refieren a: la iglesia en la economía rural; las parroquias y los párrocos en los procesos de institucionalización; las cofradías como ámbitos de construcción de los poderes locales; los curas como jueces eclesiásticos; las formas de religiosidad; los agentes e instituciones eclesiásticas en los procesos electorales, entre otras.

\section{La Iglesia y la economía rural}

Como mencionamos más arriba, los primeros estudios acerca del papel económico de la Iglesia en América Latina surgen en estrecho diálogo con las investigaciones sobre historia económica de los años ' 70 y ' 80 por, al menos, dos motivos. En primer lugar, porque los primeros estudios sobre las unidades agrarias se basaron en fuentes documentales de las órdenes religiosas que contenían un tipo de información excepcional en términos de contabilidades o inventarios. En segundo lugar, porque otros estudios, desde la historia agraria, se aproximaron a la historia de la Iglesia al preguntarse por su papel socioeconómico. Así las primeras investigaciones sobre propiedades rurales eclesiásticas del antiguo virreinato del Río de la Plata comparten una doble característica: haberse desarrollado al ritmo de los estudios sobre la hacienda colonial hispanoamericana y haber centrado su análisis en propiedades de las órdenes religiosas y, en particular, de jesuitas.

La mayoría de estos trabajos se concentraron en la Gobernación del Tucumán —y obispado del mismo nombre-, más específicamente en los Colegios y residencias jesuíticas de Córdoba, La Rioja, Catamarca, Tucumán y Salta y analizaron el funcionamiento económico de los establecimientos productivos o un aspecto en particular de ellos, como la mano de obra, el arrendamiento o alguna actividad productiva. Algunos de estos trabajos fueron compilados por Carlos Mayo, junto a otros dedicados también al análisis de las características de la mano de obra en estancias jesuíticas de Córdoba y Salta. ${ }^{10}$ Unos años

9. Barral, María Elena, «Parroquias rurales, clero y población en Buenos Aires durante la primera mitad del siglo XIX», Anuario del IEHS, núm. 20, Tandil, 2005, pp. 359-388; Barral, María Elena y Raúl Fradkin, «Los pueblos y la construcción de las estructuras de poder institucional en la campaña bonaerense (1785-1836)», Boletín del Instituto de Historia Argentina y Americana «Dr. Emilio Ravignani», núm. 27, Buenos Aires, 2005, pp. 7-48. Barral, María Elena, De sotanas por la pampa. Religión y sociedad en el Buenos Aires rural tardocolonial, Buenos Aires, Prometeo Libros, 2007.

10. Albores, Oscar, Carlos Mayo y Judith Sweeney, «Esclavos y conchabados en la Estancia de Santa Catalina, 1764-1771», en Mayo, Carlos (comp.) La historia agraria del interior. Haciendas jesuíticas de Córdoba y el Noroeste, Buenos Aires, CEAL, 1994, pp. 17-36; Mayo, Carlos, «Iglesia y esclavitud, la estancia colonial en el Río de la Plata», Revista de Historia de América, núm. 102, Colima, 1986, pp. 91-102; Mayo, Carlos, Diana Duart, y Jorge Troisi, «Nuestra Señora del Rosario. Estancia de los dominicos en la Magdalena, 1796-1818», Revista de Historia de América, núm. 120, Colima, 1995, pp. 109-123. 
más tarde fue considerado el patrimonio de los jesuitas en La Rioja y Catamarca, ${ }^{11}$ así como algunas características de su gestión en manos de la Junta de Temporalidades luego de la expulsión de la Compañía de Jesús. ${ }^{12}$ Por su parte, Nicholas Cushner ya había realizado una contribución muy importante al conocimiento de la propiedad agraria jesuita en la región, a través de una obra que integra su trilogía sobre los jesuitas y el desarrollo agrario en América del Sur. ${ }^{13}$

Por otra parte, algunos trabajos han analizado sistemáticamente las propiedades de las órdenes religiosas y de la Iglesia diocesana en una determinada región. ${ }^{14}$ Es el caso de la investigación realizada para las áreas rurales bonaerenses, la cual también se ha llevado a cabo contando con la sólida base de trabajos proporcionados por la historiografía agraria. Este estudio muestra que sus formas de inserción patrimonial en la región compartieron los rasgos básicos de la estructura agraria regional donde la gran propiedad ganadera constituía solamente una de sus modalidades y no la más habitual, con excepción de algunas unidades productivas jesuitas. Pero en términos generales, las propiedades eclesiásticas compartían, respecto de las «laicas» un patrón de diversificación en cuanto al acceso a la mano de obra, así como también el recurso permanente del arrendamiento de una parte de sus tierras. Caminando este mismo andarivel, Carlos Mayo, había estudiado la orden betlemita en Buenos Aires ${ }^{15}$-el convento-hospital Santa Catalina y todas sus empresas dependientes desde 1748 hasta 1822 - y el proceso de formación del complejo patrimonial. ${ }^{16}$

11. Quarleri, Lía, «Los jesuitas en La Rioja colonial: los mecanismos de adquisición de tierras. Integración y conflicto (1624-1767)», Memoria Americana, núm. 8, Buenos Aires, 1999, pp. 101-139; Troisi Melean, Jorge, «Una residencia, dos sistemas: el hospicio jesuita de Catamarca bajo la administración religiosa y laica», en Andes, núm. 9, Salta 1998, pp. 115-142 y «Los esclavos de los jesuitas en los Memoriales de la provincia del Paraguay (siglo XVIII), Anuario del Centro de Estudios Históricos «Profesor Carlos Segreti», Año 4, núm. 4, Córdoba, 2004, pp. 95-105.

12. Fradkin, Raúl, «Producción y arrendamiento en Buenos Aires: la Hacienda de la Chacarita, 17791784», Cuadernos de Historia Regional, núm. 15, Luján, 1992, pp. 67-98. Ciliberto, María Valeria, «Temporalidades jesuitas, capitales y crédito en el Buenos Aires tardío colonial (1767-1813)» Revista de Historia Americana y Argentina, vol. 53, núm. 2, Mendoza, 2018, pp. 11-37.

13. Cushner, Nicholas, Jesuit Ranches and the Agrarian Development of Colonial Argentina, 1650-1767, Albany, State University of New York, 1983; Lords of the lands: Sugar, wine and the Jesuit Estates of Coastal Peru, 1600-1767, Albany, State University of New York, 1980; y Farm and Factory. The Jesuit and the Development of Agrarian Capitalism in Colonial Quito, Albany, State University of New York, 1982.

14. Barral, María Elena, «Las propiedades rurales eclesiásticas en el Río de la Plata (Buenos Aires rural en el siglo XVIII y principios del XIX)», en Bodinier, Bernard; Rosa Congost, y Pablo Luna (editores), De la Iglesia al Estado. Las desamortizaciones de bienes eclesiásticos en Francia, España y América Latina, Zaragoza, Prensas Universitarias de Zaragoza (Monografías de historia rural SEHA 7), 2009, pp. 105-127.

15. Mayo, Carlos, Los Betlemitas en Buenos Aires: Convento, economía y sociedad (1748-1822), Sevilla, Junta de Andalucía, 1991.

16. Mayo analiza las estancias betlemitas y, a su vez, estos resultados son comparados con las estancias jesuitas (apareciendo diferencias en cuanto a la menor dependencia del mercado de estas últimas, así como también de una mayor utilización de mano de obra esclava en las mismas) y con estancias «laicas» (la presencia de una fuente de crédito propia en las estancias eclesiásticas, aparece como el rasgo distintivo de mayor peso) utilizando como procedimiento principal la comparación con su modelo estancia «laica» que concretó bajo la denominación «la anatomía de la estancia bonaerense». Véase Mayo, Carlos y Ángela Fernández, «Anatomía de 
Ninguna de estas aproximaciones se encontró con una Iglesia terrateniente. El panorama reconstruido acerca de las características de las propiedades eclesiásticas en la campaña de Buenos Aires puso de relieve la necesidad de indagar sobre otras formas de influencia de la Iglesia más allá de la propiedad de la tierra y de la conformación de establecimientos agropecuarios, sobre todo en un área de frontera abierta donde el acceso a la tierra y a los recursos no constituían para esta época las preocupaciones centrales. De algún modo estas conclusiones inspiraron otras líneas de investigación más atentas a otro tipo de capitales y recursos que consideraron la incidencia de las instituciones eclesiásticas en el estudio de los procesos de institucionalización.

\section{Las parroquias y los párrocos en los procesos de institucionalización}

En los últimos años la historiografía rioplatense colonial ha producido análisis muy precisos de la configuración de la autoridad eclesiástica en los pueblos rurales y el papel de los curas en las instancias de gobierno local. Al respecto, se ha avanzado en el examen del papel de los párrocos en los procesos de institucionalización, la definición de jurisdicciones religiosas y eclesiásticas, la fijación de las sedes parroquiales y el papel de las autoridades y los rituales religiosos en la lucha política local. ${ }^{17}$ Para el caso de Buenos Aires hemos podido reconstruir el despliegue de la red parroquial a lo largo del siglo XVIII y comienzos del XIX y sus transformaciones en dirección a la multiplicación de sedes de poder eclesiástico. Al comparar la evolución de las estructuras de poder institucional eclesiásticas y a su personal con las estructuras y agentes de poder judicial/policial y militar/miliciana resultó evidente que durante las décadas centrales del siglo XVIII la presencia eclesiástica fue preponderante y la designación de alcaldes de hermandad siguió los pasos trazados por la estructura parroquial. ${ }^{18}$

El papel de las parroquias en otra región de la diócesis muy cercana a la ciudad de Buenos Aires —el sudeste de Entre Ríos a fines del siglo XVIII— muestra algunas diferencias con aquel primer proceso de despliegue de la red parroquial en Buenos Aires de 1730. ${ }^{19}$ En primer lugar, porque allí la instalación de las parroquias a inicios de la década de 1780 se organizó en un contexto muy diferente al que medio siglo antes registró la

la estancia colonial bonaerense (1750-1810)», en Fradkin, Raúl (comp.), La historia agraria del Río de la Plata colonial. Los establecimientos productivos (I), Buenos Aires, CEAL, 1993, pp. 67-81. De los mismos autores: «Anatomía de la estancia eclesiástica», en Estudios-Investigaciones, núm. 22, La Plata, 1995, pp. 9-17.

17. Barral, María Elena, «Alboroto, ritual y poder en los procesos de institucionalización de un área periférica del litoral rioplatense (Gualeguay, fines del siglo XVIII)», Fronteras de la historia, vol. 17-2, Bogotá, 2012, pp. 129-158. Moriconi, Miriam, «El curato de naturales de Santa Fe. Río de la Plata, siglos XVII y XVIII», en Hispania Sacra, vol. 63, núm. 128, Madrid, 2011, pp. 433-467.

18. Barral, María Elena y Raúl Fradkin, «Los pueblos...», cit.

19. Barral, María Elena, De sotanas..., cit. y «Las parroquias del suroriente entrerriano a fines del siglo XVIII: los conflictos en Gualeguay», en Polimene, Paula (coord.), Autoridades y prácticas judiciales en el Antiguo Régimen. Problemas jurisdiccionales en el Río de la Plata, Córdoba, Tucumán, Cuyo y Chile, Rosario, Prohistoria, 2011, pp. 95-115 y «Alboroto, ritual...», cit. 
creación de las primeras parroquias de la campaña bonaerense. En las zonas rurales de Buenos Aires los párrocos fueron para muchos hombres y mujeres la primera - y tal vez la única - autoridad de un poder institucional conocida a lo largo de su vida; mientras que en Entre Ríos los párrocos se encontraron con mayores resistencias al momento de ejercer su autoridad. Por un lado porque había autoridades — judiciales, policiales y militares - previas y, además, porque el proceso de institucionalización en la región se aceleró por inmediata la instalación de los cabildos y las comandancias militares ${ }^{20}$ en el marco de un «experimento borbónico» fundación de villas como parte de una estrategia defensiva. En consecuencia, en esta región, el papel «fundacional» de las parroquias fue mucho menos evidente dado que pocos años después de su creación, debieron convivir con los cabildos y las comandancias militares.

\section{Los curas como jueces eclesiásticos}

Los trabajos que estamos comentando han puesto el foco de atención en las dinámicas políticas y religiosas en escalas reducidas y han propiciado la visualización de agentes eclesiásticos en la trama de poderes locales. ${ }^{21}$ De este modo, se han advertido prácticas en las que aparecían vinculados curas o párrocos, alcaldes ordinarios y alcaldes de la hermandad. Sin embargo, aún es frecuente la omisión de precisiones acerca de si el rol fundamental de los curas en estas pequeñas comunidades y su articulación con las élites locales se debía a las tareas anexas al ministerio sacerdotal o si, además, sus acciones vinculantes estaban ligadas al ejercicio de funciones netamente judiciales, en virtud de la acumulación en algunos de ellos de los oficios de párroco y juez eclesiástico. Aún, en general, los mapeos de las «varas» de justicia suelen considerar únicamente a la justicia real y prescindir de la justicia eclesiástica.

Asimismo, en un imaginario dominado por visiones salvíficas la función de mediación clerical ocupó el primer lugar en los estudios sobre el orden de las representaciones, en la estructuración de la vida de la comunidad y en los lenguajes jurídico-normativos. La mayor parte de los investigadores se ciñó a la mención de influencias doctrinarias o de tipo ontológico o a la incardinación entre religión y política y la raigambre teológica y cristiana de la idea de justicia. El desarrollo de este otro campo de indagación del fuero contencioso que habilita la administración de la justicia eclesiástica y el rol que les cupo a las agencias eclesiásticas que, además de potestades jurisdiccionales, tenían atribuciones judiciales está en ciernes.

20. Djenderedjian, Julio, Economía y sociedad en la Arcadia criolla. Formación y desarrollo de una sociedad de frontera en Entre Ríos, 1750-1820, Tesis de Doctorado, Universidad de Buenos Aires (Argentina), 2003.

21. Una síntesis de esta línea de investigación puede verse en: Barral, María Elena y Miriam Moriconi, «Los otros jueces: vicarios eclesiásticos en las parroquias de la diócesis de Buenos Aires durante el período colonial», en Caselli, Elisa (coord.), Justicias, agentes y jurisdicciones. De la Monarquía Hispánica a los Estados Nacionales (España y América, siglos XVI-XIX), Madrid, FCE, 2016, pp. 345-372. 
Aunque en la mayoría de los casos las cofradías han sido estudiadas en función de sus objetivos devocionales y de su papel en las fiestas y el ciclo litúrgico y festivo anual de las comunidades católicas, unos pocos trabajos han considerado su papel como espacio de experimentación del poder en diálogo con la intervención de sus miembros en otros espacios civiles de la política local como los cabildos. ${ }^{22}$

De modo que si bien su principal objetivo era devocional —el culto a una virgen o a un santo, la iluminación del Santísimo Sacramento, el rezo del rosario o el sufragio de las almas del Purgatorio - también se las ha analizado como elementos organizativos «que otorgaban a ciertos grupos de la población un lugar de encuentro, festividades comunes, proyectos de grupo, facilidades de ayuda mutua y espíritu de cuerpo» ${ }^{23}$ y de un tipo de organización con un papel decisivo en la configuración de las formas de religión local. ${ }^{24}$ Estas hermandades religiosas también pueden verse como espacios de experimentación y aprendizaje de la práctica electoral junto a otros dispositivos religiosos, como analizamos enseguida. En cada una de ellas todos los años se renovaban autoridades u oficios de distinto tipo en el marco de «Cabildos ordinarios y extraordinarios» y de procedimientos de elección sumamente regulados además de diferenciados según el tipo de autoridad que se tratara.

\section{Los agentes y las instituciones eclesiásticas en los procesos electorales}

Como consecuencia de otra intersección historiográfica —en la que convergen intereses de la historia rural, ${ }^{25}$ la historia política y la historia eclesiástica - se ha evaluado la influencia de agentes e instituciones eclesiásticas en las elecciones desarrolladas en los pueblos rurales bonaerenses entre 1810 y $1830 .{ }^{26}$ Mediante un estudio cuantitativo, se puso

22. Entre ellos mencionamos Estruch, Dolores, «Fundar, gobernar y rezar. Una aproximación a los vínculos entre sociedad, política y religión en el Jujuy colonial (1656-1776)», Runa, vol. 30, núm. 1, Buenos Aires, 2009, pp. 61-78 y Barral, María Elena, De sotanas..., cit.

23. Lockhart, James, «Organización y cambio social en la América española colonial», en Bethell, Leslie (ed.), Historia de América Latina, Tomo 4, Barcelona, Crítica, 1990, p. 84.

24. Christian, William, Religiosidad local en la España de Felipe II, Madrid, Nerea, 1991.

25. Garavaglia aborda el tema de las elecciones en San Antonio de Areco en el marco de su indagación sobre la construcción y el ejercicio del poder institucional en la campaña de Buenos Aires. Puede verse: Garavaglia, Juan Carlos, «Elecciones y luchas políticas en los pueblos de la campaña de Buenos Aires: San Antonio de Areco (1813-1844)», en Garavaglia, Juan Carlos, Construir el estado, inventar la nación. El Río de la Plata, siglos XVIII-XIX, Buenos Aires, Prometeo Libros, 2007, pp. 199-224.

26. Barral, María Elena y Agustín Galimberti, «Elecciones, gobierno local y religión en los pueblos rurales de Buenos Aires, 1815-1821», en Barral, María Elena y Raúl Fradkin (comps. 2016), Guerra y gobierno local en el espacio rioplatense (1764-1820), Luján, Edunlu, 2016, pp. 213-241; «Los «otros» curas de la revolución: algunas formas de intervención política del bajo clero en Buenos Aires (1810-1830)», en Ayrolo, Valentina y Anderson José Machado de Oliveira (coords.), en Historias de clérigos y religiosas en las Américas: conexiones entre Argentina y Brasil (siglos XVIII-XIX), Buenos Aires, Teseo, 2016, pp. 191-232 y «Espacios, instituciones y agentes 
de manifiesto distintas formas de influencia de las parroquias y de los eclesiásticos. En primer lugar, el análisis de los procesos electorales reveló que su organización territorial se montó sobre la organización jurisdiccional eclesiástica. Cada parroquia rural y cada pueblo de la campaña bonaerense, conformaron una división electoral. Al no crearse una nueva división político-administrativa, los procesos electorales se desarrollaron a partir de las dinámicas conocidas de la vida social local. De esta forma, los dispositivos electorales favorecieron, en un principio, la continuidad del ejercicio del poder de las autoridades del gobierno local y del grupo de notables de las comunidades que accedía a ellas, ya que no se modificaron los espacios ni las autoridades existentes para la realización de las elecciones. En este contexto, los párrocos se encontraron en inmejorables condiciones para representar a sus comunidades y feligresías. En segundo lugar, la investigación demostró que los curas ocuparon un lugar central en la composición de las mesas electorales. Las mismas estaban integradas por el juez principal del curato, el cura y tres vecinos de probidad. Cada sufragante debía votar frente a ellos quienes eran, a su vez, los encargados de realizar el escrutinio y calificar la pluralidad. En otras palabras, los curas rurales estaban entre los principales encargados de organizar el acto electoral desde la convocatoria de los vecinos hasta la consagración de los ganadores.

Ambas situaciones parecen haber incidido en otra situación que se ha constatado en las fuentes: los eclesiásticos se encontraban entre los principales elegidos en las elecciones rurales. ${ }^{27}$ Sin embargo, a lo largo del período analizado pueden reconocerse algunas diferencias: mientras que entre 1813 y 1819 predominaron los párrocos, luego de 1820 éstos sólo aparecían esporádicamente y comenzaban a ser reemplazados por eclesiásticos con residencia en la ciudad de Buenos Aires y que ejercían altos cargos dentro de la jerarquía eclesiástica. De esta forma si, por un lado, la participación eclesiástica había sido muy relevante durante la primera década revolucionaria, por el otro, a medida que se profundizó la experiencia electoral, la participación de los curas — y en especial de los párrocos- decrecía.

\section{Las formas de religiosidad}

En el estudio de las prácticas religiosas se hizo visible el modo en que las autoridades políticas, seculares y religiosas, de manera mancomunada dirigían su acción al logro de

religiosos en los procesos electorales. Los partidos rurales de Buenos Aires a comienzos del siglo XIX», en Favarò, Valentina, Manfredi Merluzzi y Gaetano Sabatini (eds.), Fronteras: procesos y prácticas de integración y conflictos entre Europa y América (siglos XVI-XX), Madrid, FCE, 2016, pp. 255-268.

27. En las 21 elecciones que se realizaron entre 1813 y 1828 se nombraron 259 personas como electores o representantes, de los cuales el 22,77 \% eran eclesiásticos. Esto significaba que casi uno de cada cuatro elegidos pertenecía al clero. Sin embargo, este panorama general evidenciaba claramente dos etapas siendo 1820 el año bisagra. Si en el primer subperíodo (1813-1819) los eclesiásticos electos representaron el 41,93\% del total, es decir, dos de cada cinco electos pertenecía al clero; en el segundo (1820-1828), por el contrario, este porcentaje se reducía a $12,04 \%$, mostrando un pronunciado descenso de la posibilidad que los curas rurales triunfaran en las elecciones, en Barral, María Elena y Galimberti, Agustín, «Espacios, instituciones...», cit. 
una feligresía atenta a sus obligaciones cristianas. ${ }^{28}$ Mientras que los virreyes, gobernadores y regidores de los ayuntamientos locales construyeron una densa normativa destinada a disciplinar las manifestaciones festivas, los obispos hacían lo propio alrededor de los tiempos fuertes del calendario litúrgico y de los momentos centrales en la vida individual ligados a su vez a los sacramentos: el nacimiento, el matrimonio y la muerte.

Al abordar el estudio de las instituciones ligadas a la Iglesia y de las prácticas devocionales de los pobladores rurales, éstos adquirieron una autonomía que provocaba la alarma de las autoridades eclesiásticas y civiles. ${ }^{29}$ La participación de la población rural en las diversas prácticas religiosas y en las instituciones eclesiásticas, que los convertían en depositarios de la gestión religiosa, también constituía para ellos herramientas de inserción social, política y económica en un contexto que excedía el ámbito eclesiástico.

\section{Una manera de mirar las fuentes y de pensar los abordajes}

Este segundo apartado busca sumar al recorrido «por la huella de Garavaglia» que estamos realizando, un tipo de cuestiones, si se quiere, asociadas directamente a algunas de nuestras herramientas de trabajo: las fuentes, las aproximaciones metodológicas y la perspectiva latinoamericana.

\section{Las fuentes}

Como hemos visto, las investigaciones sobre la historia rural pampeana - tanto las del propio Garavaglia como las él que dirigió e inspiró- permitieron la formulación de nuevas preguntas y la emergencia de problemas historiográficos. Uno de estos caminos es el que estamos reseñando: de la historia rural a la historia de los curas, las parroquias, sus feligreses y su religiosidad. Es probable que su capacidad de impulsar nuevas vías de indagación se asocie a la insatisfacción de las respuestas que se podían formular a partir de los trabajos disponibles y sus abordajes. Se contaba con serie de estudios realizados por historiadores católicos, laicos o sacerdotes, en su mayoría con pretensiones de apologizar la acción de la Iglesia, los obispos o los curas, quienes iniciaron un camino de identifica-

28. En distintos trabajos Garavaglia se acercó al tema de las fiestas y celebraciones: Garavaglia, Juan Carlos, «El teatro del poder: ceremonias, tensiones y conflictos en el estado colonial», Boletín del Instituto de Historia Argentina y Americana Dr. Emilio Ravignani, núm. 14, Buenos Aires, 1996, pp. 7-30; «A la nación por la fiesta»: las Fiestas Mayas en el origen de la nación en el Plata», Boletín del Instituto de Historia Argentina y Americana Dr. Emilio Ravignani, núm. 22, 2000, Buenos Aires, pp. 73-100; «Del Corpus a los Toros: fiesta, ritual y sociedad en el Río de la Plata colonial», Anuario del IEHS, núm. 16, 2001, Tandil, pp. $391-419$ y «Buenos Aires y Salta en rito cívico: la revolución y las fiestas mayas», en Andes, n. ${ }^{\circ}$ 13, Salta, 2002, pp. 173-212.

29. Puede verse Barral, María Elena y Jesús Binetti, «Las formas de religiosidad católica: algunos desplazamientos en la primera mitad del siglo XIX», en Ayrolo, Valentina; María Elena Barral y Roberto Di Stefano (coords.), Catolicismo y secularización. Argentina, primera mitad del siglo XIX, Buenos Aires, Biblos, 2012, pp. 67-91. 
ción de fuentes y de reconstrucción de episodios donde se resaltaba su influencia en la historia de la nación. ${ }^{30}$ En forma paralela y estimulados por diferentes derroteros de investigación histórica se iban saldando algunas de las deudas historiográficas sobre el clero secular, ${ }^{31}$ los conventos femeninos, ${ }^{32}$ la soberanía y el Patronato, ${ }^{33}$ el crédito eclesiástico y el sistema capellánico, ${ }^{34}$ los diezmos, ${ }^{35}$ el papel de las órdenes religiosas ${ }^{36}$ y de las cofradías, ${ }^{37}$ algunos aspectos de la reforma del clero impulsada por Rivadavia, ${ }^{38}$ entre otros.

Cabe señalar, a propósito del acceso a las fuentes que quienes nos ocupamos de estudiar algún aspecto de la vida religiosa de la diócesis de Buenos Aires anterior a $1955^{39}$ debemos sortear el obstáculo de los escasos documentos eclesiásticos. La manera de compensar esta falta de documentación ha sido por un lado recurrir a fuentes no específicas,

30. Carbia, Rómulo D. Historia eclesiástica del Río de la Plata, Buenos Aires, 1914.; Bruno, Cayetano S. D. B. Historia de la Iglesia en la Argentina, Buenos Aires, Don Bosco, 1966-1981; Zuretti, Juan Carlos Nueva Historia Eclesiástica Argentina, Buenos Aires, Itinerarium, 1972.

31. Guerrero Soriano, Cándido, Iglesia y sociedad en la Diócesis de Buenos Aires. Aspectos sociales y económico, 1700-1800, tesis presentada en la Universidad de Sevilla, 1989; Iglesias, Fidel, «A Collective Biography of the Rio de la Plata clergy, 1806-1827», Latin American Research Review, vol. 33, núm. 2, Pittsburgh, 1998; Mallo, Silvia, «Sacerdotes y feligreses en el Río de la Plata. La transición del siglos XVIII al XIX», en EstudiosInvestigaciones, núm. 22, La Plata, pp. 19-35, 1995; Di Stefano, Roberto, El púlpito y la plaza. Clero, sociedad y política. De la Monarquía católica a la República rosista, Buenos Aires, Siglo XXI, 2004; Calvo, Nancy; Roberto Di Stefano y Klaus Gallo, Los Curas de la Revolución, Buenos Aires, Emecé, 2002.

32. Braccio, Gabriela, «Una ventana hacia otro mundo. Santa Catalina de Sena: primer convento femenino de Buenos Aires», Colonial Latin American Review, núm. 9:2, Filadelfia, 2000, pp. 187-212; Fraschina, Alicia, Mujeres consagradas en el Buenos Aires colonial, Buenos Aires, Eudeba, 2010.

33. Ayrolo, Valentina: «Argumentos y prácticas patronales durante la experiencia de la centralidad política en las Provincias Unidas, 1810-1821», Anuario del Centro de Estudios Históricos «Profesor Carlos Segreti», núm. 4, Córdoba, 2004, pp. 107-122.

34. Mayo, Carlos y Peire, Jaime, «Iglesia y crédito colonial: la política crediticia de los conventos de Buenos Aires (1767-1810)», Revista de Historia de América, núm. 112, Colima, 1991, pp. 147-157; Saguier, Eduardo, «Las pautas hereditarias del régimen capellánico rioplatense», The Americas, núm. 51:3, Albany, 1995, pp. 369-392 y Caretta, Gabriela, Las capellanías colativas en Salta a fines del período colonial, como fuente de acumulación y crédito eclesiástico. Tesis de Licenciatura, unas, 1997.

35. Di Stefano, Roberto, «Dinero, poder y religión: el problema de la distribución de los diezmos en la provincia de Buenos Aires», Quinto Sol, núm. 4, Santa Rosa, pp. 87-115, 2000.

36. Mayo, Carlos, Los Betlemitas..., cit., Troisi Melean, Jorge, «Mercedarios, franciscanos y dominicos en el Río de la Plata. Estructura etaria, procedencia geográfica y patrones de carrera. Fines del período colonial», en Estudios-Investigaciones, núm. 22, La Plata, 1995, pp. 37-65; Peire, Jaime, El taller de los espejos. Buenos Aires, Claridad, 2000.

37. Fogelman, Patricia, «Una cofradía mariana urbana y otra rural en Buenos Aires a fines del período colonial», Andes núm., 11, Salta, 2000, pp. 179-207; Martínez de Sánchez, Ana María, Cofradías y obras pías en Córdoba del Tucumán, Córdoba, EDUCC, 2006; González Fasani, Ana Mónica, «El espíritu cofradiero en el Buenos Aires colonial (siglos XVII-XVIII)», en Zapico, Hilda Raquel (coord.), De prácticas, comportamientos y formas de representación social en Buenos Aires (siglos XVII-XIX), Bahía Blanca, Ediuns, 2006, pp. 261-295.

38. Urquiza, Fernando, «La Reforma Eclesiástica de Rivadavia: viejos datos y una nueva interpretación», Anuario del IEHS, núm. 13, 1998, pp. 237-246; Calvo, Nancy, «Cuando se trata de la civilización del clero. Principios y motivaciones del debate sobre la reforma eclesiástica porteña de 1822», Boletín del Instituto de Historia Argentina y Americana Dr. E. Ravignani, núm. 24, Buenos Aires, 2001, pp. 73-103.

39. El archivo de la Curia se incendió luego de los enfrentamientos entre Perón y la Iglesia. 
como litigios judiciales, sucesiones, correspondencia, actas de cabildos, diezmos, entre otras. En este punto podemos conjeturar que esa apertura al mundo «civil» que implica trabajar con estas fuentes haya favorecido, en un primer momento, una mirada desde y hacia afuera de la Iglesia y, en contraste, hayamos pasado por alto determinadas cuestiones muy específicas que luego, con el correr de los años fue necesario retomar. Sobre este punto volveremos al final del artículo.

Por otro lado, ha sido necesario recurrir a fuentes editadas antes de 1955, consultar a los archivos parroquiales microfilmados por el Centro de Historia Familiar de la Sociedad Genealógica de UTAH (o los que aún permanecen en las parroquias) o tener la posibilidad de acceder a archivos de las órdenes religiosas. Afortunadamente, parte de la documentación del clero regular (mercedarios y betlemitas) se conservan en los archivos públicos (en el Archivo General de la Nación) como consecuencia de las medidas rivadavianas conocidas como Ley de Reforma del Clero y, también de la Compañía de Jesús, antes de la expulsión, aunque, sobre todo, luego de la misma.

Los puntos de encuentro con la documentación trabajada por Garavaglia en su vasta obra son muchos. Uno de sus primeros artículos sobre el período colonial —al que ya hemos mencionado- dedicado a estudiar la estancia del Pueblo de Nuestra Señora de los Reyes Magos de Yapeyú en el período posterior a la expulsión tiene como soporte documental básico una serie de inventarios de las estancias confeccionados en el momento de la expulsión (1768) y otros posteriores $(1780,1784,1798$ y 1806) y se encuadra en el tipo de trabajos que integran el volumen compilado por Enrique Florescano en 1975 más arriba aludido. En una nota a pie de página Garavaglia se refería a las iglesias de los pueblos de misión en términos de lo que representaban de plustrabajo de los indios apropiado por la Compañía de Jesús y cuyo objetivo — la exaltación religiosa- era, básicamente, el control social. ${ }^{40}$ En la misma dirección puede entenderse la inclusión de un epígrafe en la página inicial del artículo correspondiente a la Relación de viaje a las misiones jesuíticas... de Antonio Sepp. Allí el jesuita caracterizaba el modo de castigar a los indios guaraníes como el de un padre «a sus queridos hijos» quienes «reciben el azote con la mayor paciencia y hasta agradecimiento». ${ }^{41}$ En el orden descriptivo estos agentes no eran ignorados aunque en el terreno interpretativo se convertían en «pura superestructura».

En sus trabajos posteriores sobre el conjunto de las misiones guaraníes o sobre la yerba mate, las referencias a la documentación jesuítica se multiplican (memoriales, correspondencia, cartas anuas, relaciones, historias antiguas escritas por miembros de la Compañía de Jesús, libros de cuentas) y muestran el recorrido por archivos y bibliotecas públicas (de Argentina, Paraguay, España, Perú, Bolivia, Brasil, Francia) y también por el Archivum Romanum Societatis Iesu de Roma.

Otra de las fuentes que enlaza la historia rural y la historia del catolicismo son, evidentemente, los diezmos. Garavaglia publica en 1985 un artículo en la Hispanic American

40. Garavaglia, Juan Carlos, «Las actividades...», cit.; cf. supra, nota n. ${ }^{\circ}$ 7, p. 467.

41. Ibidem, p. 464. 
Historical Review ${ }^{42}$ donde analizaba los diezmos de toda la región rioplatense: Tucumán, Cuyo, Montevideo, Santa Fe, Corrientes y Buenos Aires. Allí se toman en cuenta de manera bastante clara, las jurisdicciones episcopales ${ }^{43}$ aunque no hay ningún análisis que las haga intervenir en la explicación más que de su condición de proveedoras de la masa decimal. Se trata de un análisis que busca sistematizarla, clasificarla y compararla con el objeto de dimensionar su composición y ritmos de crecimiento o estancamiento relativos.

En este trabajo ya comenzaba a ponerse en evidencia una situación que, de algún modo, organizó su investigación durante los años subsiguientes: los diezmos que pagaba la población en la región pampeana eran mayoritariamente sobre productos agrícolas, en particular cereales, y muy secundariamente sobre ganado. ${ }^{44}$ A partir de allí se direcciona y profundiza la investigación sistemática sobre la campaña bonaerense. Pastores $y$ labradores... publicado en 1999 se convierte en una de las obras que reúnen la investigación desarrollada en buena parte de ese período. Allí se suman, entre otras fuentes, los inventarios post-mortem — 636 para el período $1751-1853$ - ${ }^{45}$ algunos de los cuales están acompañados por las mandas testamentarias. ${ }^{46}$ En este último libro el obispado recibe alguna breve consideración en términos de su enorme extensión, así como a los límites de los partidos decimales (que no se corresponden con las parroquias ni con los partidos dependientes de los cabildos) y a los momentos de administración y percepción directa o de arrendamiento. Pero su hallazgo más importante era la enorme importancia de producción agraria que el análisis de la masa decimal revelaba. Ya hemos visto el modo en que ese hallazgo también tuvo consecuencias para las investigaciones sobre la iglesia y la religiosidad en este mundo rural, pero en ese momento aún no resultaba tan evidente.

Luego el foco de observación se circunscribió a lugares más específicos, lo que le permitía estudiar a fondo determinados aspectos de la vida social y política de los pue-

42. Garavaglia, Juan Carlos, «Economic Growth and Regional Differentiations: The River Plate Region at the End of the Eighteenth Century», Hispanic American Historical Review, vol. 65, núm. 1, Durham, 1985, pp. 65-89. Se trata de un texto que ya había empezado a circular desde 1982 como ponencia (en el Congreso Americanista de Manchester) y que más tarde, traducido al español, integró el libro Economía, sociedad y regiones, Buenos Aires, Ediciones de la Flor, 1987.

43. Se trata de las diócesis de Buenos Aires y de Córdoba del Tucumán. La diócesis de Salta se crea en 1806 y se desprende del Tucumán y Cuyo (hasta el momento dependiente de Santiago de Chile) se anexa a Córdoba.

44. En los años siguientes se sumarán otros trabajos que utilizan esta fuente para debatir sobre la estructura agraria de la campaña bonaerense: García Belsunce, César, «Diezmos y producción agrícola en el Buenos Aires virreinal», Investigaciones y Ensayos, núm. 38, Buenos Aires, 1988, pp. 317-355 y Amaral, Samuel y José M. Ghío, «Diezmos y producción agraria. Buenos Aires, 1750-1800», Revista de bistoria económica, Año VIII, núm. 3, Madrid, 1990, pp. 619-647. Habrá que esperar una década para que la fuente sea retomada en el campo de los estudios sobre el catolicismo. Puede verse Di Stefano, Roberto, «Dinero...», cit.

45. Garavaglia, Juan C., «Un siglo de estancias en la campaña de Buenos Aires, 1751-1853», Hispanic American Historical Review, vol. 79, núm. 4, Durham, 1999, pp. 703-734.

46. Garavaglia me «regaló» el listado de estas sucesiones con su signatura topográfica muchas de las cuales me permitieron llevar a cabo un estudio sobre la piedad mortuoria. Barral, María Elena, De sotanas..., cit., cap. 7 . 
blos de la campaña de Buenos Aires. San Antonio de Areco fue otro de sus laboratorios y esta investigación sostenida durante otra década dio como fruto otro libro. ${ }^{47}$ Para reconstruir las redes sociales en Areco, Garavaglia debió recurrir a los archivos parroquiales con la mala suerte de que precisamente esos libros de bautismos, matrimonios y defunciones de esta parroquia no habían sido microfilmados por los mormones. Por esta razón Juan Carlos se acercó hasta esta ciudad y logró fotografiar la documentación que se encontraban en la iglesia parroquial más antigua del partido. Para poder hacerlo, tuvo la fortuna de contar con la «cordialidad típicamente iralndesa» de su párroco el Padre Tomas O'Farrel, como el mismo Garavaglia lo recuerda en la introducción al libro referido. Pero resulta llamativo que una parte importante de la justificación que el propio autor encuentra en «haberse detenido tanto tiempo», en la historia de Areco está, justamente, en su archivo parroquial, en la riqueza y la antigüedad de sus fondos documentales. ${ }^{48}$ Otra parte de la fundamentación de este tipo de reconstrucción microanalítica y monumental a la vez, — dada la enorme cantidad de información relevada, procesada y analizada - era un objetivo: demostrar cómo a $80 \mathrm{~km}$ de Buenos Aires, «la arquitectura local de los mecanismos de poder que acompañó la construcción estatal dio resultados tan complejos, y en muchos sentidos, diferentes a lo de la capital porteña».49

Por último, no deja de ser elocuente de un cambio de percepción —entre aquel Yapeyú y este Areco- acerca de la relevancia de la acción eclesial el capítulo que lleva el título «La cruz, la vara y la espada». Allí incorpora de manera sistemática la dimensión religiosa y eclesiástica al estudio del poder local y de la construcción estatal a lo largo del siglo XIX.

Jorge Gelman decía que Juan Carlos Garavaglia elegía mirar los fenómenos históricos desde los bordes o desde los márgenes y así iluminar unas historias en general desconocidas, «su mirada se enfocó no tanto en los estancieros más destacados (a quienes también estudió porque no dejó nada sin estudiar para entender a esa sociedad!) sino sobre todo en los pobladores más humildes, en los paisanos, en los peones, en los mecanismos de reciprocidad campesina, en las influencias de migrante tucumano sobre sus prácticas «culturales, etc.» ${ }^{50}$ Este abordaje también compone un legado: una manera de analizar los conflictos, una manera de pensar el poder, una valoración acerca de la escritura. ¿Puedo alguien que haya leído «Pobres y ricos: Cuatro historias edificantes sobre el conflicto social en la campana bonaerense (1820-1840)» no sentir una fuerte empatía con Liberato Pintos? ${ }^{31}$ un pobre/rico pastor de San Vicente a quien conocimos sólo porque un historiador decidió que su historia iluminaba nuestra percepción del siglo XIX. Y si se

47. Garavaglia, Juan Carlos, San Antonio de Areco (1680-1880). Un pueblo de la campaña, del Antiguo Régimen a la «modernidad» argentina, Rosario, Prohistoria, 2009.

48. Garavaglia, Juan Carlos, San Antonio de Areco..., cit., p. 16.

49. Ibidem

50. Gelman, Jorge, «Juan Carlos Garavaglia y la historia económico-social de América Latina. Algunas lecciones de historia y de vida», Prohistoria, núm. 28, Rosario, 2017, pp. 281-287.

51. Garavaglia, Juan Carlos, «"Pobres y ricos" Cuatro historias edificantes sobre el conflicto social en la campana bonaerense (1820-1840)», Entrepasados, núm. 15, Buenos Aires, 1998, pp. 19-40. 
trata de escribir de modo atractivo y con profundidad histórica la historia de Libertato puede ser un buen ejemplo:

Tenemos aquí así la paradoja «aparente» de Liberato Pintos, un hombre realmente «pobre» en bienes materiales, simple labrador y pasto, pero, que es rico en redes relacionales de viejo arraigo en la localidad. Podemos decir que Liberato se pasea por las aguas relacionales de San Vicente como un pez en un tranquilo estanque..$^{52}$

Estos juegos de escalas, desde lo local a lo global, su trabajo «en lo micro», en una interacción casi adictiva con la documentación histórica, puso en evidencia en su obra, la fertilidad y potencialidad explicativa de muchas de estas historias «mínimas».

\section{El punto de observación: entre lo local y lo global}

En febrero de 2017, a un mes de su fallecimiento, Raúl Fradkin y Jorge Gelman escribían acerca de Garavaglia: «Desde muy joven, entonces, realizó investigaciones que cambiaron —en muchos casos radicalmente — las formas que teníamos de comprender la historia latinoamericana. Porque Juan Carlos fue uno de nuestros pocos y mejores historiadores latinoamericanistas y, sin duda, ello definió su lugar singular dentro del campo historiográfico argentino.» $>^{53}$

Juan Carlos fue un historiador latinoamericanista y parte de la originalidad y potencia de sus trabajos se deben precisamente a este punto de observación entre lo local y lo global en clave latinoamericana. Una de las definiciones que, a mi criterio, resuelve mejor esta perspectiva la proporciona William Taylor en el libro Entre el proceso global y el conocimiento local. En su introducción ofrece una explicación de una profundidad equivalente a su sencillez: «Por lo general, al abordar la historia mexicana he intentado entrar por en medio — viendo hacia adelante y hacia atrás, hacia arriba y hacia abajo, y hacia un lado, y el otro, entre el conocimiento local y el proceso global, entre las elites y la plebe, y entre las acciones individuales y los patrones de grupos- en busca de contrapuntos y conexiones a través del espacio y el tiempo. El propósito ha sido ampliar la mirada sobre el pueblo mexicano, pensando en lo grande y en lo pequeño, lo local, lo municipal, lo regional, lo provincial, lo virreinal, lo nacional, lo global».54

La trayectoria que estamos historizando es sumamente expresiva de una época historiográfica en América Latina de la que Juan Carlos Garavaglia formó parte: una historia de desplazamientos de objetos de investigación materiales hacia otros socio-culturales. Una parte de esta deriva historiográfica que comienza en los «años dorados» de las inves-

52. Ibidem, p. 42

53. Fradkin, Raúl y Gelman, Jorge, «Juan Carlos Garavaglia, hasta siempre», Anuario del IEHS, núm. 32 (1), Tandil, 2017, pp. 7-18.

54. Taylor, William, Entre el proceso global y el conocimiento local. Ensayos sobre el Estado, la sociedad y la cultura en el México del siglo XVIII, México, UAM-Miguel Ángel Porrúa, 2003, p. 8. 
tigaciones sobre la hacienda mexicana se convertirá en una de las vertientes que alimentaron la renovada historia de la Iglesia. Distintos recorridos dan cuenta de este camino para el caso novohispano que siempre ha iluminado de modo especial nuestras investigaciones. Los trabajos de David Brading y William Taylor ${ }^{55}$ y otras trayectorias explicaron diferentes aspectos de la vida religiosa y eclesiástica colonial y sus vínculos con la economía y la política. Me refiero al conjunto de investigaciones sobre el clero secular y sus instituciones, la dimensión judicial de la acción eclesial, el crédito eclesiástico, el papel de las parroquias y las cofradías, de las órdenes religiosas o el monacato femenino, de la cultura religiosa y de la religiosidad popular, entre otros temas. ${ }^{56}$ Desde los años noventa muchos de los trabajos sobre la Iglesia novohispana se centraron en el siglo XVIII y en la independencia y sus conclusiones han contribuido a la reflexión y al estudio del papel de la religión y de los clérigos en la conflictividad social y política; de los vínculos entre párrocos y feligreses en estos mismos contextos y de la necesidad de inscribir este vínculo en una historia más larga de negociación, obediencia y desobediencia. ${ }^{57}$

Como ya lo hemos mencionado, en los inicios de esta renovación de temas y problemas de investigación, fueron, en gran medida, los estudios centrados en los sistemas agrarios los que dieron las pistas para reconsiderar el papel de la Iglesia como administradora de propiedades agrarias, como rentista, como prestamista o como comerciante. Algunos historiadores tomaron en cuenta esos datos relevantes que aparecían en las fuentes y en

55. Tanto en la obra de Brading como en la de Taylor puede reconocerse un desplazamiento de sus investigaciones sobre las haciendas, la conflictividad social hacia temas directamente vinculados a la historia religiosa. Una muestra de este recorrido en el caso de Brading son las obras: Haciendas y Ranchos en el Bajío, León, 1700-1860, México, Enlace Grijalbo, 1988 y Una Iglesia asediada. El obispado de Michoacán, 1749-1810, México, FCE, 1994. En Taylor, una serie de trabajos testimonian del mismo proceso: «Haciendas coloniales en el Valle de Oaxaca», en Florescano, Enrique (coord.), Haciendas..., cit., pp. 71-104; Embriaguez, homicidio y rebelión en las poblaciones coloniales mexicanas, México, D.F, FCE, 1987 y Ministros de lo sagrado: sacerdotes y feligreses en el México del siglo XVIII, Colegio de Michoacán-Secretaria de Gobernación-El Colegio de México, Zamora, Michoacán, 1999.

56. Distintos artículos y libros dan cuenta de las principales perspectivas de investigación desarrolladas en México alrededor de la Historia de la Iglesia y el catolicismo. Entre ellos puede verse Martínez López-Cano, María del Pilar (coord.), La Iglesia en Nueva España. Problemas y perspectivas de investigación, México, UNAM, 2010, donde los miembros del seminario interinstitucional de Historia Política y Económica de la Iglesia (IIHUNAM y el Instituto de Ciencias Sociales y Humanidades «Alfonso Vélez Pliego» de la Universidad Autónoma de Puebla) llevan a cabo una reflexión crítica sobre la producción historiográfica en torno del estudio de la Iglesia en la época virreinal. Puede verse asimismo los siguientes estados del arte: Aguirre, Rodolfo, «Historia social de la Iglesia y la religiosidad novohispanas. Tendencias historiográficas», Fronteras de la Historia, vol 5-1/2010, pp. 143-156; Ibarra, Ana Carolina, «La historiografía sobre la Iglesia y el clero», en Ávila, Alfredo y Virginia Guedea (coords.), La independencia de México, temas e interpretaciones, México, UNAM, 2007, pp. 117-144; y «Deberes y haberes de la historia religiosa en México», en Alicia Mayer y Ernesto de la Torre Villar (eds.), Religión, poder y autoridad en la Nueva España, México, UNAM, 2004, pp. 429-439.

57. Taylor, William, «Bandolerismo e insurrección. Agitación social en el centro de Jalisco, 1790-1816», en Katz, F., Revuelta, rebelión y revolución. La lucha rural en México del siglo XVI al siglo XX, 1, México, Era, 1990, pp. 187-223 y Ministros de lo sagrado...; Van Young, Eric, The Other Rebellion: Popular Violence, Ideology, and the Mexican Struggle for Independence, 1810-1821, Stanford, Stanford University Press, 2001; Guzmán Pérez, Moisés, «En el nombre del Señor». Banderas rojinegras en la guerra de independencia novohispana, 1811-181», Estudios de Historia Novohispana, núm. 31, Ciudad de México, 2004, pp. 39-72. 
sus análisis y los convirtieron en problemas historiográficos sobre los cuales hasta ese momento se sabía muy poco.

En este sentido Eric van Young anticipó parte de este proceso de innovación historiográfica. En su balance sobre la historiografía de la hacienda mexicana — de fines de la década de 1980—, proponía «salir de la hacienda» para conocer mejor las estructuras agrarias rurales mexicanas. La parte final de este artículo conformaba una propuesta a la que denominó Algunas sugerencias para investigaciones futuras en la cual convocaba a la realización de estudios que hicieran hincapié en la historia social de las estructuras agrarias y, en particular, advertía sobre la necesidad de evaluar de modo específico el papel de los intermediarios rurales en el marco de la preocupación más general orientada a dilucidar la dinámica que asumieron los diversos mecanismos de control social en el campo. Allí también formulaba una serie de interrogantes que vale la pena recordar. Para lograr una explicación más completa y compleja de su historia rural, aseguraba:

Nuestro panorama histórico de los distritos rurales no estará completo hasta que conozcamos más sobre los intermediarios rurales — sacerdotes, comerciantes provinciales, funcionarios reales menores, arrieros, funcionarios de las haciendas y rancheros- que establecían muchos de los vínculos entre terratenientes y jornaleros sin tierras, blancos e indígenas, productores y consumidores..$^{58}$

En mi opinión Van Young invitaba a «salir de la hacienda» para luego volver a ella. $\mathrm{Y}$ esto no parece haber sucedido en todos los casos. Por el contrario, y al calor de muchas influencias algunos de estos estudios se transformaron en campos de investigación autónomos y no siempre volvieron al tipo de investigaciones desarrolladas en aquellos tramos iniciales y que habían proporcionado las pistas para avanzar en distintas direcciones. El sentido de la mayoría de estos desplazamientos tuvo una clara dirección: de los estudios de historia económica a los estudios de historia social y cultural.

Los movimientos de Juan Carlos Garavaglia no se insinúan tan unidireccionales. Se desplazó en el tiempo, en el espacio y en las dimensiones a las cuales atendió de manera preferencial. Como queriendo encontrar el hilo que hilvanaba temas y sujetos Fradkin se pregunta: «¿qué era lo que unía el estudio del comercio, la yerba mate, el trigo y el maíz, a Yapeyú, Tepeaca y Areco, los ponchos, los ganados, los mercados, las relaciones de producción, las tecnologías, la agrimensura, los ecosistemas, la fiscalidad, la demografía, la formación de los estados y las naciones, los rituales, la justicia, los pueblos?».99

Cuenta Fradkin que Garavaglia contestaba a esta pregunta siempre de la misma manera, como al pasar, «una cosa te lleva a la otra», pero él sospecha que en el fondo de todo estaba un interés por los hombres y las mujeres del común. No por casualidad escri-

58. Van Young, Eric, «La historia rural de México desde Chevallier: historiografía de la hacienda colonial», en Cárdenas, E. (comp.), Historia económica de México, México, FCE, 1989, p. 422.

59. Fradkin, Raúl, «Indicios y conjeturas: La formación de un historiador original», Prohistoria, núm. 28, Rosario, 2017, p. 259. 
bieron —o mejor dicho, habían escrito en el año 1992 - juntos un bellísimo libro que casi copia esta respuesta imaginada. ${ }^{60}$

\section{A modo de cierre}

Entre 2012 y 2015 por iniciativa de la UPP y de Edhasa y con la coordinación general de Juan Manuel Palacio se publicaron los seis tomos de la Historia de la Provincia de Buenos Aires. A través de esta obra se buscaba ofrecer un estudio integral sobre la provincia de Buenos Aires desde el siglo XVI hasta la actualidad. Armonizando los aportes de diferentes autores y autoras provenientes de distintas áreas y tematizando los problemas centrales de la historia de este espacio se buscaba producir un material destinado «a estudiantes universitarios de ciencias sociales y humanidades, de institutos de profesorado, junto con otro público más de profesionales diversos y otro "público educado" ». ${ }^{61} \mathrm{Ha}$ bían pasado setenta años del clásico trabajo de Ricardo Levene sobre la Historia de la provincia de Buenos Aires y formación de sus pueblos (de 1940/41) y la propuesta era totalmente novedosa dado que se alejaba aquel formato consistente en la sumatoria de historias de los pueblos. En aquella versión cada historiador local consagrado, contaba la historia del «pueblo» en cuestión, dando cuenta de sus diferentes períodos y desarrollando los diferentes aspectos de su vida social, política, económica, institucional y cultural. La Iglesia católica y sus curas tenían en cada una de ellas su lugar.

El tomo 2 de la Colección de EDHASA/UNIPE «De la conquista a la crisis de 1820» dirigido por Raúl Fradkin ${ }^{62}$ fue una oportunidad para elaborar a través de sus once capítulos y en un registro de alta divulgación, una suerte de composiciones, generales y eruditas a la vez, sobre diferentes dimensiones de la vida social y política del territorio provincial. Cada capítulo puede verse también como la oportunidad para una puesta el día sobre los avances de diferentes líneas de investigación. La historia de la Iglesia católica en ese período tuvo su capítulo junto a otros sobre el territorio; la economía; la ciudad puerto, su vida social, política e intelectual; las fronteras y las relaciones interétnicas; la vida familiar y las relaciones de género, raza y clase y las guerras y la movilización social para la guerra.

Juan Carlos Garavaglia fue el encargado de inaugurar el volumen construyendo una visión global del conjunto de procesos que fueron convirtiendo a la ciudad de Buenos Aires en provincia y de las relaciones sociales, diversas y cambiantes que configuraron esa sociedad. Las capillas se hacen presentes a la hora de explicar las formas de ocupación

60. Garavaglia, Juan Carlos y Fradkin, Raúl, Hombres y mujeres de la colonia, Buenos Aires, Sudamericana, 1992.

61. Berardi, Pedro, «Buenos Aires: modelo para (re)armar. Un diálogo con Juan Manuel Palacios a propósito de Historia de la Provincia de Buenos Aires», PolHis, Año 6, núm. 11, Mar del Plata, 2013, pp. 264-270.

62. Fradkin, Raúl (coord.), Historia de la Provincia de Buenos Aires. De la Conquista a la crisis de 1820, tomo 2, Buenos Aires: UNIPE/EDHASA, 2012. 
del territorio en las voces de los Robertson — «núcleos en torno a los cuales el hombre gregario puede estar seguro de hallar asociación»—, en los escritos del cabildo compeliendo a los «vagos y ociosos» a vivir «bajo cruz y campana» y en sus emplazamientos en las cercanías de las postas de los caminos a Perú y Chile. Los curas párrocos también aparecen en el medio de la explicación referida al armazón institucional, como los primeros agentes enviados desde la ciudad y como «principio y fin» de casi todos los actos públicos que ritmaban la vida de los súbditos de la monarquía. Están allí, como parte de la triada de poder local, en las elecciones soportando la lenta construcción de las bases de la ciudadanía moderna de muy distintas maneras, como ya lo hemos caracterizado en páginas anteriores.

El derrotero reseñado en este artículo, que partió de la historia rural bonaerense, «descubrió» y «recortó» a las parroquias, a las cofradías y a los curas rurales. Este recorte posibilitó mostrar su importancia en los procesos de articulación y control social, integrar a las sedes y autoridades religiosas en los dispositivos de los gobiernos locales y comprender el papel fundacional de los mismos en la construcción de un orden político provincial en el siglo XIX. Estas reconstrucciones permitieron unir la historia tardocolonial con la de la revolución y las décadas subsiguientes y reconocer el rol de algunas figuras provenientes del mundo religioso y clerical como soportes del cambio político: en las elecciones, en la prensa, en la guerra o en las legislaturas. A su vez estos estudios incorporaron a determinadas instituciones — como las hermandades y las cofradías — en la reflexión sobre los ámbitos de sociabilidad, las estrategias de los grupos de poder locales como «notables» de los pueblos, las formas de resolución de conflictos en la arena infrajudicial y los ámbitos de experimentación de la práctica política-electoral en contextos antiguo-regimentales.

Pero quizás este recorte que permitió «sacar» a estos agentes e instituciones de los claustros y restituirlos al mundo social y político del que hacían parte, a su vez minimizó la relevancia de su pertenencia a jurisdicciones específicas, diluyó sus lazos con las altas autoridades político-religiosas o desconoció la circulación de sus carreras en cartografías más amplias (rioplatenses, americanas y de las monarquías ibéricas). ${ }^{63}$

Sin embargo, y pese a que hemos iniciado un camino de restitución, ${ }^{64}$ si se quiere, de algunas jurisdicciones quizás algo descuidadas, nuestro balance sigue siendo positivo. A partir de un profundo conocimiento del mundo campesino preindustrial y a través de un paciente y monumental trabajo de archivo Garavaglia descubrió una sociedad ignorada por casi todos: hombres, mujeres, familias, tradiciones, costumbres, conflictos y relaciones de poder hasta el momento desconocidas. Estos hallazgos pusieron en entredicho

63. Aquí remito, antes que a cualquier otro, a mis propios trabajos de la etapa doctoral. Barral, María Elena, De sotanas..., cit.

64. Barral, María Elena, «Estructuras eclesiásticas, poblamiento e institucionalización en la diócesis de Buenos Aires durante el período colonial», en Barral, María Elena y Marco Antonio Silveira (coords.), Historia, poder e instituciones: diálogos entre Brasil y Argentina, Rosario, Prohistoria, 2015, pp. 165-190. Puede verse el dossier coordinado por Ayrolo, Valentina; María Elena Barral, y Guillermo Wilde, «Avances de los estudios sobre la iglesia y la religión en tres jurisdicciones eclesiásticas: Buenos Aires, Asunción y Córdoba (siglos XVIIIXIX)» Anuario del IHES, núm. 31, 2016, pp. 89-191. 
viejos mitos y nos permitieron imaginar un mundo de creencias y prácticas religiosas y de sotanas polvorientas.

\section{Bibliografía}

Aguirre, Rodolfo, «Historia social de la Iglesia y la religiosidad novohispanas. Tendencias historiográficas», Fronteras de la Historia, vol. 5-1, Bogotá, 2010, pp. 143-156.

Albores, Oscar; Carlos Mayo y Judith Sweeney, «Esclavos y conchabados en la Estancia de Santa Catalina, 1764-1771», en Mayo, Carlos (comp.), La historia agraria del interior. Haciendas jesuíticas de Córdoba y el Noroeste, Buenos Aires, CEAL, pp. 17-36.

Amaral, Samuel y José M. Ghío, «Diezmos y producción agraria. Buenos Aires, 1750-1800», Revista de historia económica, Año VIII, núm. 3, Madrid, 1990, pp. 619-647.

Ayrolo, Valentina: «Argumentos y prácticas patronales durante la experiencia de la centralidad política en las Provincias Unidas, 1810-1821», Anuario del Centro de Estudios Históricos «Profesor Carlos Segreti», núm. 4, Córdoba, 2004, 107-122.

Ayrolo, Valentina; María Elena Barral y Guillermo Wilde (coords.), «Avances de los estudios sobre la iglesia y la religión en tres jurisdicciones eclesiásticas: Buenos Aires, Asunción y Córdoba (siglos XVIII-XIX)», Anuario del IHES, núm. 31, 2016, pp. 89-191.

Barral, María Elena, «Parroquias rurales, clero y población en Buenos Aires durante la primera mitad del siglo XIX», Anuario del IEHS, núm. 20, Tandil, 2005, pp. 359-388.

-, De sotanas por la pampa. Religión y sociedad en el Buenos Aires rural tardocolonial, Buenos Aires, Prometeo Libros, 2007.

—, «Las propiedades rurales eclesiásticas en el Río de la Plata (Buenos Aires rural en el siglo XVIII y principios del XIX)», en Bodinier, Bernard; Congost, Rosa y Luna, Pablo (eds.), De la Iglesia al Estado. Las desamortizaciones de bienes eclesiásticos en Francia, España y América Latina, Zaragoza, Prensas Universitarias de Zaragoza (Monografías de historia rural SEHA 7), 2009, pp. 105-127.

-, «Las parroquias del suroriente entrerriano a fines del siglo XVIII: los conflictos en Gualeguay», en Polimene, Paula (coord.), Autoridades y prácticas judiciales en el Antiguo Régimen. Problemas jurisdiccionales en el Río de la Plata, Córdoba, Tucumán, Cuyo y Chile, Rosario, Prohistoria, 2011, pp. 95-115.

—, «Alboroto, ritual y poder en los procesos de institucionalización de un área periférica del litoral rioplatense (Gualeguay, fines del siglo XVIII)», Fronteras de la bistoria, vol. 17-2, Bogotá, 2012, pp. 129-158.

—, «Estructuras eclesiásticas, poblamiento e institucionalización en la diócesis de Buenos Aires durante el período colonial», en Barral, María Elena y Silveira, Marco Antonio (coords.), Historia, poder e instituciones: diálogos entre Brasil y Argentina, Rosario, Prohistoria, 2015, pp. 165-190.

Barral, María Elena y Jesús Binetti, «Las formas de religiosidad católica: algunos desplazamientos en la primera mitad del siglo XIX», en Ayrolo, Valentina; María Elena Barral y Roberto Di Stefano (coords.), Catolicismo y secularización. Argentina, primera mitad del siglo XIX, Buenos Aires, Biblos, 2012, pp. 67-91.

Barral, María Elena y Raúl Fradkin, «Los pueblos y la construcción de las estructuras de poder institucional en la campaña bonaerense (1785-1836)», Boletín del Instituto de Historia Argentina y Americana «Dr. Emilio Ravignani», núm. 27, Buenos Aires, 2005, pp. 7-48. 
Barral, María Elena y Agustín Galimberti, «Elecciones, gobierno local y religión en los pueblos rurales de Buenos Aires, 1815-1821», en Barral, María Elena y Fradkin, Raúl, Guerra y gobierno local en el espacio rioplatense (1764-1820), Luján, Edunlu, 2016, pp. 213-241.

—, «Espacios, instituciones y agentes religiosos en los procesos electorales. Los partidos rurales de Buenos Aires a comienzos del siglo XIX», en Favarò, Valentina, Merluzzi Manfredi y Sabatini, Gaetano (eds.), Fronteras: procesos y prácticas de integración y conflictos entre Europa y América (siglos XVI-XX), FCE, Madrid, 2016, pp. 255-268.

—, «Los «otros» curas de la revolución: algunas formas de intervención política del bajo clero en Buenos Aires (1810-1830)», en Ayrolo, Valentina y Anderson José Machado de Oliveira (coords.), en Historias de clérigos y religiosas en las Américas: conexiones entre Argentina y Brasil (siglos XVIII-XIX), Buenos Aires, Teseo, 2016, pp. 191-232.

Barral, María Elena y Moriconi, Miriam, «Los otros jueces: vicarios eclesiásticos en las parroquias de la diócesis de Buenos Aires durante el período colonial», en Caselli, Elisa (coord.), Justicias, agentes y jurisdicciones. De la Monarquía Hispánica a los Estados Nacionales (España y América, siglos XVI-XIX), Madrid, FCE, 2016, pp. 345-372.

Berardi, Pedro, «Buenos Aires: modelo para (re)armar. Un diálogo con Juan Manuel Palacios a propósito de Historia de la Provincia de Buenos Aires», PolHis, Año 6, núm. 11, Mar del Plata, 2013, pp. 264-270.

Braccio, Gabriela, «Una ventana hacia otro mundo. Santa Catalina de Sena: primer convento femenino de Buenos Aires», Colonial Latin American Review, núm. 9:2, Filadelfia, 2000, pp. 187 212.

Brading, David, Haciendas y Ranchos en el Bajío, León, 1700-1860, México, Enlace Grijalbo, 1988.

—, Una Iglesia asediada. El obispado de Michoacán, 1749-1810, México, FCE, 1994.

Bruno, Cayetano S. D. B., Historia de la Iglesia en la Argentina, Buenos Aires, Don Bosco, 19661981.

Calvo, Nancy, «Cuando se trata de la civilización del clero. Principios y motivaciones del debate sobre la reforma eclesiástica porteña de 1822», Boletín del Instituto de Historia Argentina y

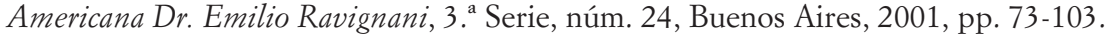

—, Roberto Di Stefano y Klaus Gallo, Los Curas de la Revolución, Buenos Aires, Emecé, 2002.

Carbia, Rómulo D., Historia eclesiástica del Río de la Plata, Buenos Aires, 1914.

Caretta, Gabriela, Las capellanias colativas en Salta a fines del periodo colonial, como fuente de acumulación y crédito eclesiástico. Tesis de Licenciatura, UNSA, 1997.

Christian, William, Religiosidad local en la España de Felipe II, Madrid, Nerea, 1991.

Ciliberto, María Valeria, «Temporalidades jesuitas, capitales y crédito en el Buenos Aires tardío colonial (1767-1813)» Revista de Historia Americana y Argentina, vol. 53, núm. 2, Mendoza, 2018, pp. 11-37.

Cushner, Nicholas, Lords of the lands: Sugar, wine and the Jesuit Estates of Coastal Peru, 1600-1767, Albany, State University of New York, 1980.

-, Farm and Factory. The Jesuit and the Development of Agrarian Capitalism in Colonial Quito, Albany, State University of New York, 1982.

-, Jesuit Ranches and the Agrarian Development of Colonial Argentina, 1650-1767, Albany, State University of New York, 1983.

Di Stefano, Roberto, «Dinero, poder y religión: el problema de la distribución de los diezmos en la provincia de Buenos Aires», Quinto Sol, núm. 4, Santa Rosa, 2000, pp. 87-115. 
- El púlpito y la plaza. Clero, sociedad y política. De la Monarquía católica a la República rosista, Buenos Aires, Siglo XXI, 2004.

Djenderedjian, Julio, Economía y sociedad en la Arcadia criolla. Formación y desarrollo de una sociedad de frontera en Entre Ríos, 1750-1820, Tesis de Doctorado, Universidad de Buenos Aires (Argentina), 2003.

Estruch, Dolores, «Fundar, gobernar y rezar. Una aproximación a los vínculos entre sociedad, política y religión en el Jujuy colonial (1656-1776)», Runa, vol. 30, núm. 1, Buenos Aires, 2009, pp. 61-78.

Florescano, Enrique (coord.), Haciendas, latifundios y plantaciones en América Latina, México DF, Siglo XXI, 1975.

Fogelman, Patricia, «Una cofradía mariana urbana y otra rural en Buenos Aires a fines del período colonial», Andes, núm. 11, Salta, 2000, pp. 179-207.

Fradkin, Raúl, «Producción y arrendamiento en Buenos Aires: la Hacienda de la Chacarita, 17791784», en Cuadernos de Historia Regional, núm. 15, Luján, 1992, pp. 67-98.

—, «La historia agraria y los estudios de establecimientos productivos en Hispanoamérica: una mirada desde el Río de la Plata», en Fradkin, Raúl (comp. y estudio preliminar), La historia agraria del Río de la Plata colonial. Los establecimientos productivos I, Buenos Aires, CEAL, 1993, pp. 7-44.

—, «Caminos abiertos en la pampa. Dos décadas de renovación de la historia rural rioplatense desde mediados del siglo XVIII a mediados del XIX», en Gelman, Jorge (comp.), La historia económica argentina en la encrucijada. Balances y perspectivas, Buenos Aires, Prometeo Libros, 2006.

—, (coord.), Historia de la Provincia de Buenos Aires. De la Conquista a la crisis de 1820, tomo 2, Buenos Aires, UNIPE/EDHASA, 2012.

—, «Indicios y conjeturas: La formación de un historiador original», Prohistoria, vol. 28, Rosario, 2017, pp. 257-275.

Fradkin, Raúl y Jorge Gelman, «Juan Carlos Garavaglia, hasta siempre», Anuario del IEHS, núm. 32 (1), Tandil 2017, pp. 7-18.

Fraschina, Alicia, Mujeres consagradas en el Buenos Aires colonial, Buenos Aires, Eudeba, 2010.

Garavaglia, Juan Carlos, «Las actividades agropecuarias en el marco de la vida económica del pueblo de indios de Nuestra Señora de los Santos Reyes Magos de Yapeyú, 1768-1806», en Florescano, Enrique (coord.), Haciendas, latifundios y plantaciones en América Latina, México DF, 1975, pp. 464-485.

-, «Economic Growth and Regional Differentiations: The River Plate Region at the End of the Eighteenth Century», Hispanic American Historical Review, vol. 65, núm. 1, Durham, 1985, pp. 65-89.

—, Economía, sociedad y regiones, Buenos Aires, Ediciones de la Flor, 1987.

—, «El teatro del poder: ceremonias, tensiones y conflictos en el estado colonial», Boletín del Instituto de Historia Argentina y Americana Dr. Emilio Ravignani, núm. 14, Buenos Aires, 1996, pp. 7-30.

—, «De mingas y convites: la reciprocidad campesina entre los paisanos rioplatenses», Anuario del IEHS, núm. 12, Tandil, 1997, pp. 131-139.

—, «"Pobres y ricos" Cuatro historias edificantes sobre el conflicto social en la campana bonaerense (1820-1840)», Entrepasados, núm. 15, Buenos Aires, 1998, pp. 19-40.

—, «Un siglo de estancias en la campaña de Buenos Aires, 1751-1853», Hispanic American Historical Review, vol. 79, núm. 4, Durham, 1999, pp. 703-734. 
—, «A la nación por la fiesta»: las Fiestas Mayas en el origen de la nación en el Plata», en Garavaglia, Juan Carlos, Boletín del Instituto de Historia Argentina y Americana Dr. Emilio Ravignani, núm. 22, 2000, Buenos Aires, pp. 73-100.

-, «Del Corpus a los Toros: fiesta, ritual y sociedad en el Río de la Plata colonial», Anuario del IEHS, núm. 16, 2001, Tandil, pp. 391-419.

—, «Buenos Aires y Salta en rito cívico: la revolución y las fiestas mayas», Andes, n. ${ }^{\circ}$ 13, Salta, 2002, pp. 173-212.

—, «Elecciones y luchas políticas en los pueblos de la campaña de Buenos Aires: San Antonio de Areco (1813-1844)», en Garavaglia, Juan Carlos, Construir el estado, inventar la nación. El Río de la Plata, siglos XVIII-XIX, Buenos Aires, Prometeo Libros, 2007, pp. 199-224.

—, San Antonio de Areco (1680-1880). Un pueblo de la campaña, del Antiguo Régimen a la «modernidad» argentina, Rosario Prohistoria, 2009.

Garavaglia, Juan Carlos y Raúl Fradkin, Hombres y mujeres de la colonia, Buenos Aires, Sudamericana, 1992.

García Belsunce, César, «Diezmos y producción agrícola en el Buenos Aires virreinal», Investigaciones y Ensayos, núm. 38, Buenos Aires, 1988, pp. 317-355.

Gelman, Jorge, «Juan Carlos Garavaglia y la historia económico-social de América Latina. Algunas lecciones de historia y de vida», Prohistoria, núm. 28, Rosario, 2017, pp. 281-287.

González Fasani, Ana Mónica, «El espíritu cofradiero en el Buenos Aires colonial (siglos XVIIXVIII)», en Zapico, Hilda Raquel (coord.), De prácticas, comportamientos y formas de representación social en Buenos Aires (siglos XVII-XIX), Bahía Blanca, Ediuns, 2006, pp. 261-295.

Guerrero Soriano, Cándido, Iglesia y sociedad en la Diócesis de Buenos Aires. Aspectos sociales y económico, 1700-1800, tesis presentada en la Universidad de Sevilla, 1989.

Guzmán Pérez, Moisés, «En el nombre del Señor». Banderas rojinegras en la guerra de independencia novohispana, 1811-181», Estudios de Historia Novohispana, núm. 31, Ciudad de México, 2004, pp. 39-72.

Halperín Donghi, Tulio, «Una estancia en la campaña de Buenos Aires, Fontezuela, 1753-1809», en Florescano, Enrique (coord.), Haciendas, latifundios y plantaciones en América Latina, México DF, 1975, pp. 446-463.

Iglesias, Fidel, «A Collective Biography of the Rio de la Plata clergy, 1806-1827», Latin American Research Review, vol. 33, núm. 2, Pittsburgh,1998.

Ibarra, Ana Carolina, «Deberes y haberes de la historia religiosa en México», en Alicia Mayer y Ernesto de la Torre Villar (eds.), Religión, poder y autoridad en la Nueva España, México, UNAM, 2004, pp. 429-439.

Ibarra, Ana Carolina, «La historiografía sobre la Iglesia y el clero», en Ávila, Alfredo y Guedea, Virginia (coords.), La independencia de México, temas e interpretaciones, México, UNAM, 2007, pp. 117-144.

Lockhart, James, Organización y cambio social en la América española colonial, en Bethell, Leslie (ed.), Historia de América Latina, Tomo 4, Barcelona, Crítica, 1990.

Mallo, Silvia, «Sacerdotes y feligreses en el Río de la Plata. La transición del Siglo XVIII al XIX», Estudios-Investigaciones, núm. 22, La Plata, pp. 19-35, 1995.

Martínez López-Cano, María del Pilar (coord.), La Iglesia en Nueva España. Problemas y perspectivas de investigación, México, UNAM, 2010.

Martínez de Sánchez, Ana María, Cofradías y obras pías en Córdoba del Tucumán, Córdoba, EDUCC, 2006. 
Mayo, Carlos, «Iglesia y esclavitud, la estancia colonial en el Río de la Plata», Revista de Historia de América, núm. 102, Colima, 1986, pp. 91-102.

—, Los Betlemitas en Buenos Aires: Convento, economía y sociedad (1748-1822), Junta de Andalucía, Sevilla, 1991.

—, (coord.), La historia agraria del interior. Haciendas jesuíticas de Córdoba y el Noroeste, Buenos Aires, Centro Editor de América Latina, 1994.

Mayo, Carlos y Jaime Peire, «Iglesia y crédito colonial: la política crediticia de los conventos de Buenos Aires (1767-1810)», Revista de Historia de América, núm. 112, Colima, 1991, pp. 147157.

Mayo, Carlos y Ángela Fernández, «Anatomía de la estancia colonial bonaerense (1750-1810)», en Fradkin, Raúl (comp.), La historia agraria del Río de la Plata colonial. Los establecimientos productivos (I), Buenos Aires, Centro Editor de América Latina, 1993, pp. 67-81.

—, «Anatomía de la estancia eclesiástica», Estudios-Investigaciones, núm. 22, La Plata, 1995, pp. 9-17.

Mayo, Carlos, Duart, Diana y Troisi, Jorge, «Nuestra Señora del Rosario. Estancia de los dominicos en la Magdalena, 1796-1818», Revista de Historia de América, n. ${ }^{\circ} 120$, Colima, 1995, pp. 109 123.

Moriconi, Miriam, «El curato de naturales de Santa Fe. Río de la Plata, siglos XVII y XVIII», en Hispania Sacra, vol. 63, núm. 128, Madrid, 2011, pp. 433-467.

Peire, Jaime, El taller de los espejos, Buenos Aires, Claridad, 2000.

Quarleri, Lía, «Los jesuitas en La Rioja colonial: los mecanismos de adquisición de tierras. Integración y conflicto (1624-1767)», Memoria Americana, núm. 8, Buenos Aires, 1999, pp. 101-139.

Saguier, Eduardo, «Las pautas hereditarias del régimen capellánico rioplatense», en The Americas, núm. 51:3, Albany, 1995, pp. 369-392.

Taylor, William, «Haciendas coloniales en el Valle de Oaxaca», en Florescano, Enrique (coord.), Haciendas, latifundios y plantaciones en América Latina, Mexico DF, 1975, pp. 71-104.

-, Embriaguez, homicidio y rebelión en las poblaciones coloniales mexicanas, México, DF, FCE, 1987.

—, «Bandolerismo e insurrección. Agitación social en el centro de Jalisco, 1790-1816», en Katz, F., Revuelta, rebelión y revolución. La lucha rural en México del siglo XVI al siglo XX, 1, México, Era, 1990, pp. 187-223.

-, Ministros de lo sagrado: sacerdotes y feligreses en el México del siglo XVIII, Colegio de Michoacán-Secretaria de Gobernación-El Colegio de México, Zamora, Michoacán, 1999.

-, Entre el proceso global y el conocimiento local. Ensayos sobre el Estado, la sociedad y la cultura en el México del siglo XVIII, México, UAM-Miguel Ángel Porrúa, 2003.

Troisi Melean, Jorge, «Mercedarios, franciscanos y dominicos en el Río de la Plata. Estructura etaria, procedencia geográfica y patrones de carrera. Fines del período colonial», Estudios-Investigaciones, núm. 22, La Plata, 1995, pp. 37-65.

—, «Una residencia, dos sistemas: el hospicio jesuita de Catamarca bajo la administración religiosa y laica», Andes, núm. 9, Salta, 1998, pp. 115-142.

-, «Los esclavos de los jesuitas en los Memoriales de la provincia del Paraguay (siglo XVIII), Anuario del Centro de Estudios Históricos «Profesor Carlos Segreti», Año 4, núm. 4, 2004, Córdoba, pp. 95-105.

Urquiza, Fernando, «La Reforma Eclesiástica de Rivadavia: viejos datos y una nueva interpretación», Anuario del IEHS, núm. 13, Tandil, 1998, pp. 237-246. 
Van Young, Eric, «La historia rural de México desde Chevallier: historiografía de la hacienda colonial», en Cárdenas, E. (comp.), Historia económica de México, México, FCE, 1989.

-, The Other Rebellion: Popular Violence, Ideology, and the Mexican Struggle for Independence, 1810-1821, Stanford, Stanford University Press, 2001.

Zuretti, Juan Carlos Nueva Historia Eclesiástica Argentina, Buenos Aires, Itinerarium, 1972. 